\title{
Endogenous interferon-beta but not interferon-alpha or interferon-lambda levels in nasal mucosa predict clinical outcome in critical COVID-19 patients independent of viral load
}

\author{
Soraya Maria Menezes, Marcos Braz, Veronica Llorens-Rico Joost Wauters, Johan Van \\ Weyenbergh
}

Affiliations:

SMM, MB, JVW: Laboratory of Clinical and Epidemiological Virology, Dept. of Microbiology, Immunology and Transplantation, Rega Institute of Medical Research, KU Leuven, Leuven, Belgium.

VLR: Laboratory of Bacteriology, Dept. of Microbiology, Immunology and Transplantation, Rega Institute of Medical Research, KU Leuven, Leuven, Belgium.

JW: Laboratory for Clinical Infectious and Inflammatory Disorders, Department of Microbiology, Immunology and Transplantation, KU Leuven, Leuven, Belgium.

\begin{abstract}
:
Although the subject of intensive preclinical and clinical research, controversy on the protective vs. deleterious effect of interferon (IFN) in COVID-19 remains. Some apparently conflicting results are likely due to the intricacy of IFN subtypes (type I: IFN-alpha/beta, type III: IFN-lambda), timing and mode of administration (nebulized/subcutaneous) and clinical groups targeted (asymptomatic/mild, moderate, severe/critical COVID-19). Within the COntAGlouS (COvid-19 Advanced Genetic and Immunologic Sampling) clinical trial, we investigated endogenous type I and type III IFNs in nasal mucosa as possible predictors of clinical outcome in critical patients, as well as their correlation to SARS-CoV-2 viral load, using nCounter technology. We found that endogenous IFN-beta expression in the nasal mucosa predicts clinical outcome, independent of viral replication or Apache II score, and should be considered as a prognostic tool in a precision medicine approach of IFN therapy in COVID-19 clinical management.
\end{abstract}


medRxiv preprint doi: https://doi.org/10.1101/2021.03.23.21253748; this version posted March 26, 2021. The copyright holder for this preprint (which was not certified by peer review) is the author/funder, who has granted medRxiv a license to display the preprint in perpetuity. It is made available under a CC-BY-ND 4.0 International license .

\section{INTRODUCTION}

Although the subject of intensive preclinical and clinical research, controversy on the protective vs. deleterious effect of interferon (IFN) in COVID-19 remains. Some apparently conflicting results are likely due to the intricacy of IFN subtypes (type I: IFN-alpha/beta, type III: IFN-lambda), timing and mode of administration (nebulized/subcutaneous) and clinical groups targeted (asymptomatic/mild, moderate, severe/critical COVID-19).

Two recent phase-2 clinical trials ${ }^{1,2}$ reporting the use of type I and type III IFN achieved their primary clinical and virological outcomes in hospitalized and ambulatory COVID-19 patients, respectively. As set forth previously ${ }^{3}$, understanding the different kinetics of endogenous IFN production in mild and severe COVID-19 patients, relative to viral replication, will help identify the therapeutic window. Thus, endogenous IFN(s) add another layer of complexity to the COVID-19 IFN conundrum but have been understudied in critical (ICU) patients.

\section{PATIENTS AND METHODS}

The COntAGlouS trial (COvid-19 Advanced Genetic and Immunologic Sampling; an in-depth characterization of the dynamic host immune response to coronavirus SARS-CoV-2) proposes a transdisciplinary approach to identify host factors resulting in hyper-susceptibility to SARS-CoV-2 infection. Within this prospective clinical trial (NCT04327570), we investigated viral and host transcriptomes in the nasal mucosa of patients with COVID-19 critical disease, admitted to the intensive care unit (ICU) at University Hospitals Leuven, Belgium. Nasal swabs were collected from 57 critical COVID-19 patients on admission in ICU and/or first bronchoscopy. RNA was extracted and mRNA levels for IFN-beta (IFNB1 gene), IFN-alpha (IFNA2 gene) and IFN-lambda (IFNL2 and IFNL3 genes) were quantified by nCounter technology (Nanostring) as previously described ${ }^{4}$. Viral load (total SARS-CoV-2 transcripts corresponding to Surface glycoprotein, Nucleoprotein, Envelope protein, Membrane protein, ORF1AB, ORF3A and ORF7A) was quantified as described ${ }^{5}$, using digital transcriptomics (nCounter, Nanostring) previously validated in a large cohort of acute respiratory infection ${ }^{6}$. All ICU patients received standard-of-care treatment (corticosteroids, anticoagulants, vasopressors and/or antibiotics, in addition to ventilation/ECMO) but none received IFN treatment.

\section{RESULTS AND DISCUSSION}

As primary endpoint, we investigated length of stay in the ICU (ranging from 3 to 74 days) with type I and III IFN as predictors, using Kaplan-Meier curves. As shown in Fig. 1A-B-C, IFNB1 transcript levels (Hazard ratio (HR) 0.30 95\% Cl[0.16-0.56], $\mathrm{p}=0.0001$ ) but not IFNA2 (HR 0.82 95\% Cl[0.46-1.50], $\mathrm{p}=0.53$ ) or IFNL2/IFNL3 transcript levels (HR $0.6795 \% \mathrm{Cl}[0.35-1.27]$, $\mathrm{p}=0.22$ ), nor viral load (HR $1.1395 \% \mathrm{CI}[0.64-$ 1.98], $p=0.68$, data not shown) predicted the length of ICU stay. Multivariable regression confirmed IFNB1 levels $(\beta=0.45$ [0.24-0.67], $p=0.0002)$ and Acute Physiology and Chronic Health Evaluation (Apache) II score $(\beta=1.06[0.49-1.65], p=0.0009)$ as independent predictors, whereas viral load, age, gender, BMI or Charlson Comorbidity index were not. Moreover, IFNB1 levels also predicted worse 
medRxiv preprint doi: https://doi.org/10.1101/2021.03.23.21253748; this version posted March 26, 2021. The copyright holder for this preprint (which was not certified by peer review) is the author/funder, who has granted medRxiv a license to display the preprint in perpetuity. It is made available under a CC-BY-ND 4.0 International license .

clinical outcome measured by maximal WHO ordinal scale or maximal oxygen support (Mann-Whitney, $p=0.027$ and $p=0.0068$, respectively), as well as a composite score (discharge to rehabilitation centre, hospital stay $>60$ days or death; Mann-Whitney $\mathrm{p}=0.040$ ). Noteworthy, $45 \%$ (5 of 11) of IFNB1-positive patients required ECMO vs. only 9\% (4 of 46) of IFNB1-negative patients. The total days on ECMO was also higher in IFNB1+ patients (median 24.0 vs. 10.5 days, Mann-Whitney $\mathrm{p}=0.016$ ). IFNB1 levels also predicted multi-organ involvement, another hallmark of critical COVID-19, as measured by Sequential Organ Failure Assessment (SOFA) score (median SOFA score 7 for IFNB1-negative vs. 12 for IFNB1+, Mann-Whitney $\mathrm{p}=0.0072$ ). Surprisingly, IFNB1 levels were not correlated to viral load (Fig. 1D), in contrast to IFNA2 ( $\mathrm{r}=0.45, \mathrm{p}=0.0007$ ) and IFNL2/IFNL3 ( $\mathrm{r}=0.47, \mathrm{p}=0.0003)$.

In conclusion, endogenous IFN-beta production in the nasal mucosa predicts clinical outcome, independent of viral replication or Apache II score, and should be considered as a prognostic tool in a precision medicine approach of IFN therapy in COVID-19 clinical management. 

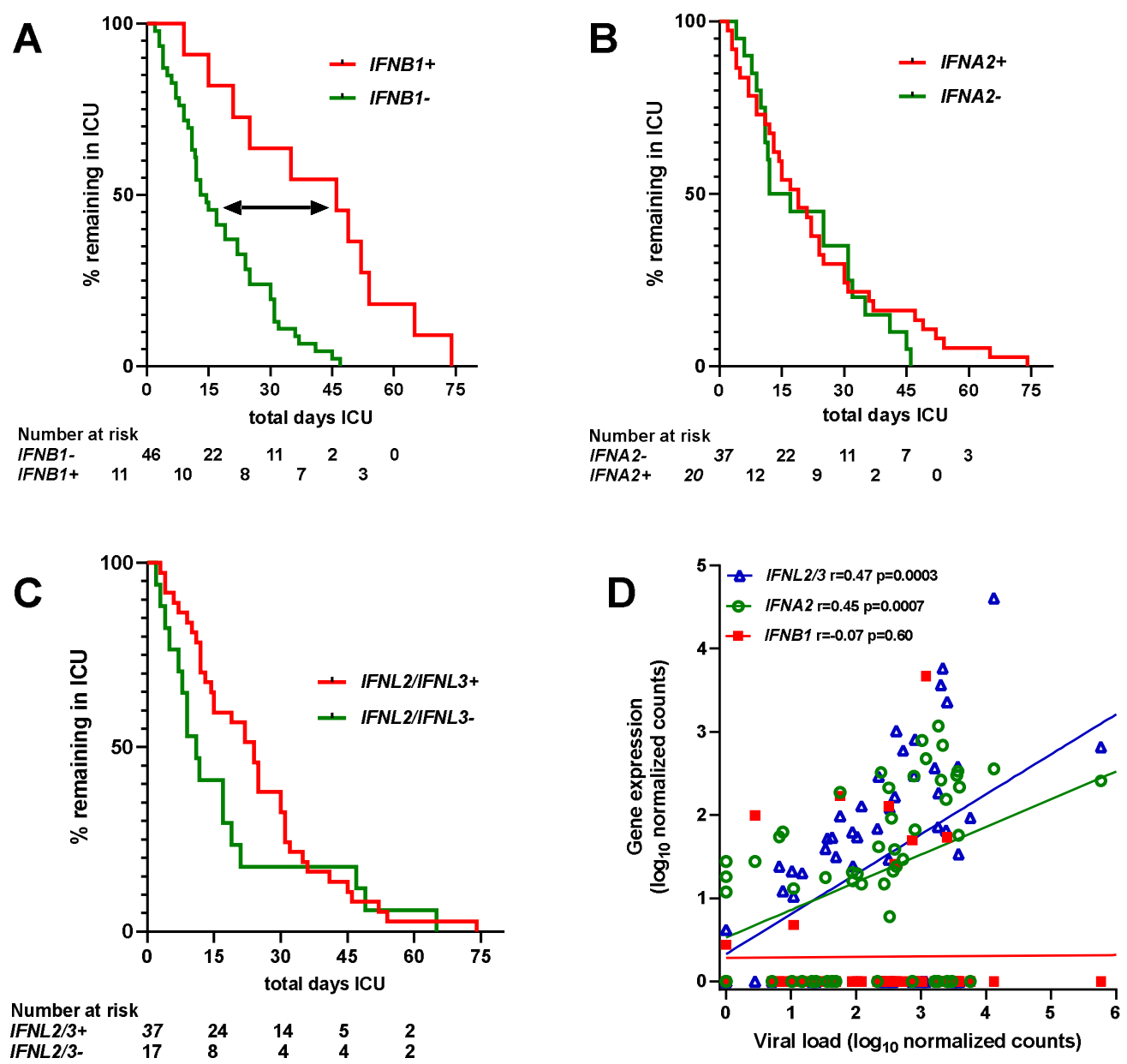

Fig. 1: Upper respiratory tract IFN-beta transcript levels, but not IFN-alpha or IFN-lambda transcript levels, predict length of ICU stay in critical COVID-19 patients. Kaplan-Meier curves of (A) IFNB1positive vs. IFNB1-negative, (B) IFNA2-positive vs. IFNA2-negative, and (C) IFNL2/3-positive vs. IFNL2/3negative ICU patients were compared using Log-rank test (*** $\mathrm{p}=0.0001$ for IFNB1, not significant for IFNA2, IFNL2/IFNL3 or viral load, not shown). (D) Viral load was correlated to IFNB1, IFNA2, and IFNL2/IFNL3 transcripts (Spearman correlation). Viral load and IFNL2/IFNL3 data were missing from 3 patients $(n=54)$. 
medRxiv preprint doi: https://doi.org/10.1101/2021.03.23.21253748; this version posted March 26, 2021. The copyright holder for this preprint (which was not certified by peer review) is the author/funder, who has granted medRxiv a license to display the preprint in perpetuity. It is made available under a CC-BY-ND 4.0 International license.

\section{References:}

1. Feld et al. Peginterferon lambda for the treatment of outpatients with COVID-19: a phase 2, placebocontrolled randomised trial. Lancet Respir Med 2021 https://doi.org/10.1016/S2213-2600(20)30566-X

2. Monk et al. Safety and efficacy of inhaled nebulised interferon beta-1a (SNG001) for treatment of SARS-CoV-2 infection: a randomised, double-blind, placebo-controlled, phase 2 trial. Lancet Respir Med 2021 https://doi.org/10.1016/S2213-2600(20)30511-7

3. Park \& Iwasaki. Type I and Type III Interferons - Induction, Signaling, Evasion, and Application to Combat COVID-19. Cell Host \& Microbe 2020. https://doi-org/10.1016/i.chom.2020.05.008

4. Fukutani et al. In situ Immune Signatures and Microbial Load at the Nasopharyngeal Interface in Children with Acute Respiratory Infection. Front Microbiol. 2018 Nov 9;9:2475. https://doiorg/10.3389/fmicb.2018.02475

5. Ackermann et al. Pulmonary Vascular Endothelialitis, Thrombosis, and Angiogenesis in Covid-19. N Engl J Med. 2020 Jul 9;383(2):120-128. https://doi-org/10.1056/NEJMoa2015432

6. Bouzas et al. Diagnostic accuracy of digital RNA quantification versus real-time PCR for the detection of respiratory syncytial virus in nasopharyngeal aspirates from children with acute respiratory infection. J Clin Virol. 2018 Sep;106:34-40. https://doi-org/10.1016/i.jcv.2018.07.003 